\title{
BLOOD GASES IN ROUTINE ANAESTHESIA
}

\author{
Jone Chang, M.D., F.R.C.P.(c) ${ }^{*}$
}

IN PRoviding ANAESTHESIA for routine cases for surgery, practising anaesthetists assume that the patient is in satisfactory clinical condition during anaesthesia as long as the respiration appears adequate, the cardiovascular system is stable, and the general colour is good. This study was originally initiated to confirm the belief that these clinical impressions were correct.

\section{METHOD}

Patients were chosen at random for general anaesthesia. There were no prior decisions as to the choice of anaesthetic agents, technique, or types of patients (age or physical condition). There were 17 thoracotomies out of the 75 cases studied. Arterial blood samples were taken from the brachial or radial artery prior to the induction of anaesthesia; subsequently samples were taken at 30minute intervals either as single arterial punctures or from an indwelling needle in the radial artery. Blood samples were analysed for $\mathrm{Pa}_{0_{2}}, \mathrm{~Pa}_{\mathrm{CO}_{2}}, \mathrm{pH}$, and $\mathrm{HCO}_{3}$ by the Astrup method (Radiometer and Instrumentation Laboratories). Minute volumes and tidal volumes were measured with a Wright respirometer.

\section{Preoperative $\mathrm{Pa}_{\mathrm{O}_{2}}$}

\section{Results}

In all the cases studied, a preoperative arterial blood sample was taken prior to the induction of anaesthesia. All the patients were given the usual preoperative medication. The results are shown in Table I and Figure 1. As shown by Bendixen, ${ }^{1}$ the $\mathrm{Pa}_{\mathrm{O}_{2}}$ level gradually decreased as the age increased. The average

TABLE I

\begin{tabular}{lcccc}
\multicolumn{5}{c}{ Preoperative $\mathrm{Pa}_{\mathbf{O}_{2}}(\mathrm{~mm} \mathrm{Hg})$} \\
\hline \hline \multicolumn{1}{c}{ Age } & No. & High & Low & Average \\
\hline Under 30 & 10 & 116 & 67 & 95.1 \\
$31-40$ & 10 & 110 & 73 & 90.6 \\
$41-50$ & 20 & 94 & 56 & 80.3 \\
$51-60$ & 15 & 101 & 57 & 77.2 \\
$61-70$ & 9 & 89 & 62 & 76.2 \\
Over 70 & 10 & 90 & 63 & 75.6 \\
Average & 74 & 101.5 & 63.0 & 81.9 \\
\hline
\end{tabular}

arterial oxygen tension diminished from $95.1 \mathrm{~mm} \mathrm{Hg}$ for the age group under 30 to $75.6 \mathrm{~mm} \mathrm{Hg}$ for the age group over 70 . The mean arterial oxygen tension for the whole group was $81.9 \mathrm{~mm} \mathrm{Hg}$. Less than 10 per cent of the cases showed an arterial oxygen tension above $100 \mathrm{~mm} \mathrm{Hg}$.

${ }^{\circ}$ Department of Surgery, Division of Anaesthesia, Faculty of Medicine, University of British Columbia, and Department of Anaesthesia, Vancouver General Hospital. 


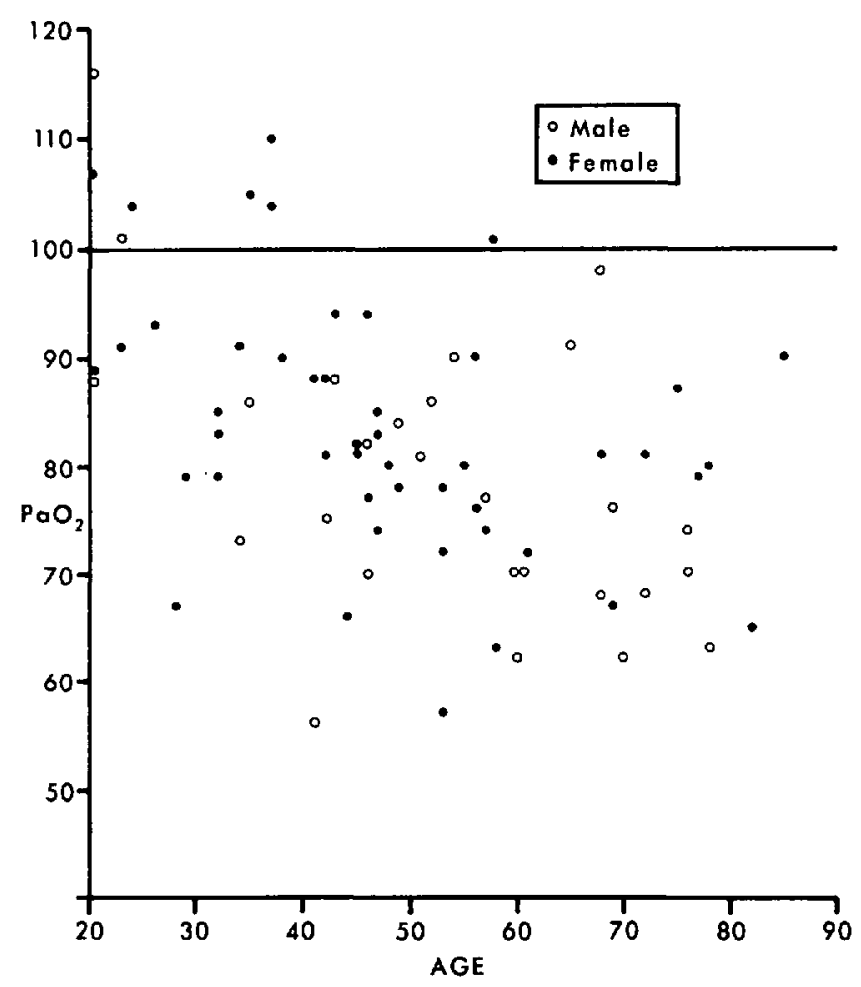

Figure 1. Preoperative arterial oxygen tension with usual premedication.

TABLE II

12 Chest Cases, Endobronchial. Technique

\begin{tabular}{lrrrrrrr}
\hline \hline & \multicolumn{3}{c}{ Pleura closed } & & \multicolumn{3}{c}{ Pleura open } \\
\cline { 2 - 3 } & high & low & average & high & low & average \\
\hline $\mathrm{PaO}_{2}(\mathrm{~mm} \mathrm{Hg})$ & 205 & 54 & 116 & & 112 & 62 & 87 \\
$\mathrm{PaCO}_{2}(\mathrm{~mm} \mathrm{Hg})$ & 41 & 21 & 31.3 & 62 & 25 & 34.2 \\
\hline
\end{tabular}

\section{Thoracotomy cases}

There were 17 cases in which thoracotomy was performed. Most of the patients were anaesthetized by the endobronchial technique with the use of either the Carlens or the Gordon-Green tube. The anaesthetic agents for maintenance were cyclopropane or nitrous oxide and halothane. The percentage of inspired oxygen varied in the different cases.

The arterial oxygen tension results after induction of anaesthesia and before opening of the pleura were mostly above $100 \mathrm{~mm} \mathrm{Hg}$. The average was $116 \mathrm{~mm}$ Hg. Once the pleura was opened and the lung collapsed, the arterial oxygen tension decreased in practically all cases. The average arterial oxygen tension was $87 \mathrm{~mm} \mathrm{Hg}$, as shown by Table II and Figures 2, 3, and 4 . In some of the cases, the use of 100 per cent oxygen in the inspired mixture while the lung was col- 


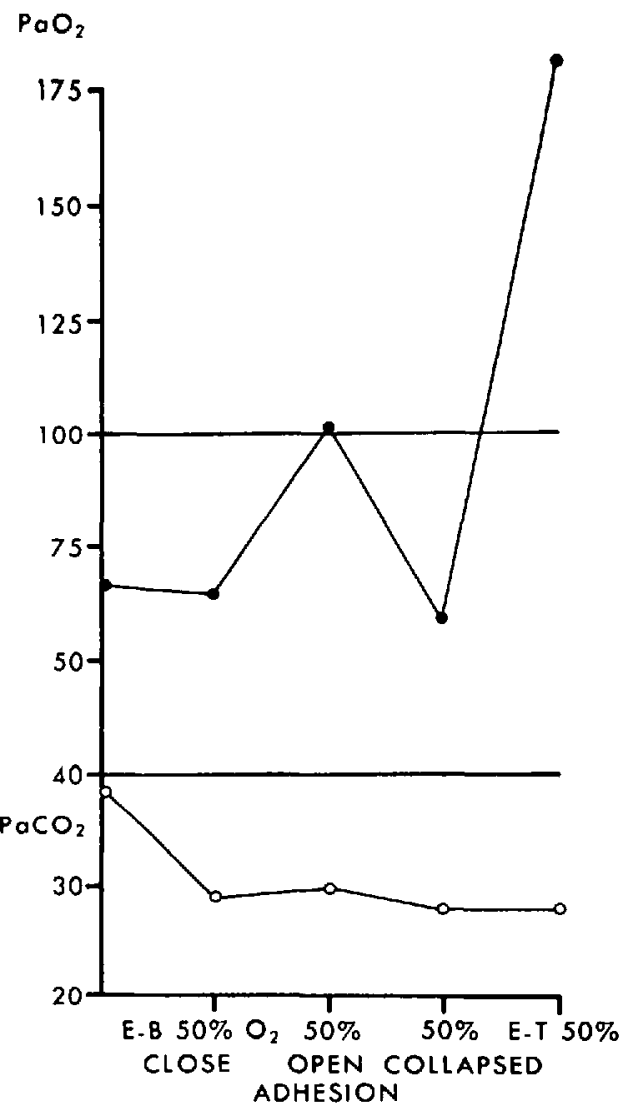

Figure 2. Diagram of a thoracotomy procedure, showing changes in arterial oxygen and carbon dioxide tension with the pleura closed and open using endobronchial anaesthesia. ET = endotracheal, EB = endobronchial, cLOSE = pleura closed, oPEN $=$ pleura open, aDHEsion $=$ lung adherent.

lapsed gave inconsistent results, the arterial oxygen tensions were either increased, unchanged, or decreased, as seen in Figure 5.

Once the endobronchial was converted to endotrachial anaesthesia with the collapsed lung partially or completely inflated, the arterial oxygen tension improved very markedly, and when 100 per cent oxygen was administered the arterial oxygen tension reached a level of over $400 \mathrm{~mm} \mathrm{Hg}$, as illustrated in Figures 2, 3, and 5 .

The arterial carbon dioxide tensions were variable once the pleura was opened and the lung collapsed. Two patients showed a moderate rise in the carbon dioxide tension to 50 and $62 \mathrm{~mm} \mathrm{Hg}$, while others showed either minor increase or decrease. The average arterial carbon dioxide tension rose from 31.3 to 34.2 $\mathrm{mm} \mathrm{Hg}$, as illustrated in Table II. 


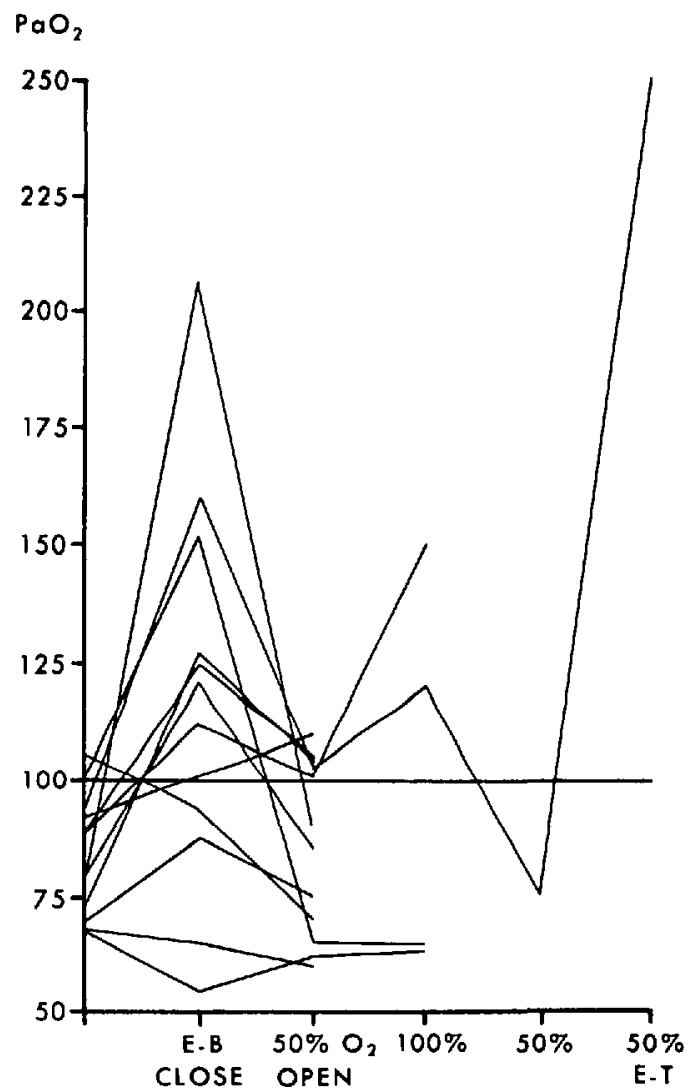

Figure 3. Changes in arterial oxygen tensions during thoracotomy in 12 cases using 50 per cent and 100 per cent inspired oxygen. Abbreviations as in Figure 2.

Cases with intact thorax

The results from patients who did not have a thoracotomy were separated and compared as to the percentage of inspired oxygen and techniques of administration, as for example spontaneous respiration versus intermittent positive pressure respiration.

In the cases where the inspired oxygen concentrations were below 50 per cent, the patients breathing spontaneously gave higher arterial oxygen tension readings than the ones ventilated with the Bird respirator. Nearly all the patients breathing spontaneously had arterial oxygen tensions over $100 \mathrm{~mm} \mathrm{Hg}$, while practically all the arterial carbon dioxide tensions were over $40 \mathrm{~mm} \mathrm{Hg}$, as illustrated in Tables III and IV and Figures 6, 7, and 8. The average arterial oxygen tensions for 30 and 60 minutes with spontaneous respiration were 143 and $152 \mathrm{~mm} \mathrm{Hg}$ respectively, as compared with 128 and $111 \mathrm{~mm} \mathrm{Hg}$ with the Bird respirator.

The patients ventilated on the Bird respirator were divided into those receiving an inspired oxygen concentration of 50 per cent and those receiving a concentration below 50 per cent. Ventilation with 50 per cent oxygen consistently produced superior arterial oxygen tension. The average arterial oxygen tensions for 30 and 
J. CHANG: BLOOD GASES IN ROUTINE ANAESTHESIA

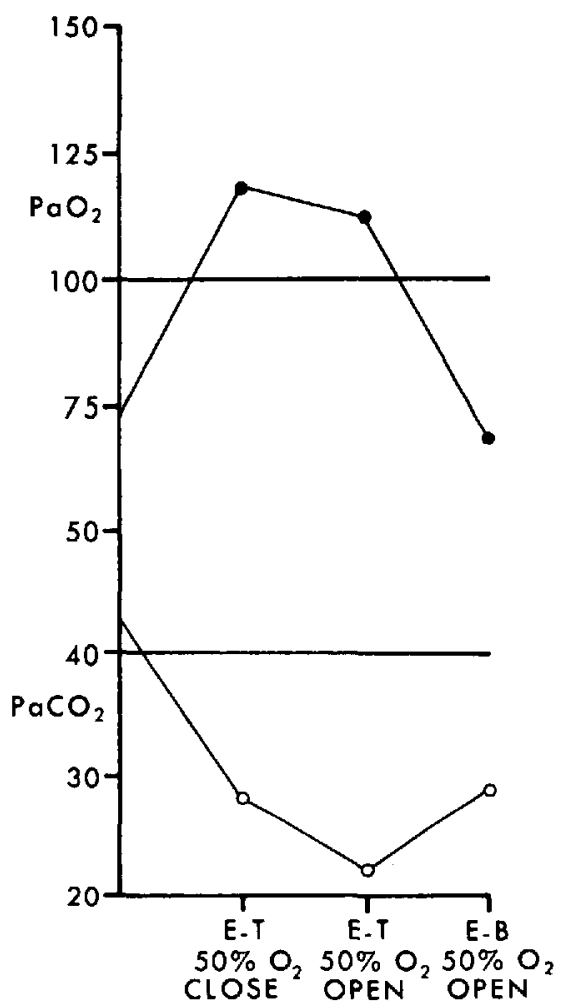

FIgure 4. Changes in arterial oxygen and carbon dioxide tensions during a thoracotomy procedure. Abbreviations as in Figure 2.

60 minutes were 128 and $113 \mathrm{~mm} \mathrm{Hg}$ respectively with oxygen below 50 per cent and 169 and $177 \mathrm{~mm} \mathrm{Hg}$ with oxygen concentration 50 per cent, as seen in Table $\mathrm{V}$ and Figure 9 . The arterial carbon dioxide tensions were all below preoperative levels and below $40 \mathrm{~mm} \mathrm{Hg}$.

Finally, cyclopropane in a closed-circuit carbon dioxide absorption technique was compared with nitrous oxide with halothane or other supplements. In cases where cyclopropane was administered in a closed circuit, the inspired oxygen concentrations were all over 50 per cent. The average arterial oxygen tension was $294 \mathrm{~mm} \mathrm{Hg}$, being the highest of the groups compared, as illustrated in Table VI and Figure 10.

The $\mathrm{pH}$ levels were measured in all the cases. The changes in $\mathrm{pH}$ were correlated directly with the arterial carbon dioxide tension. As the carbon dioxide tension was increased, the $\mathrm{pH}$ decreased, and conversely the $\mathrm{pH}$ increased as the carbon dioxide tension decreased.

Patients breathing spontaneously all showed increases in arterial carbon dioxide tension. These patients exhibited marked differences in ventilating volumes. The measured minute volumes varied from $3900 \mathrm{ml}$ to $8100 \mathrm{ml}$ per minute. In case no. 59 , when the patient was breathing with a tidal volume of $300 \mathrm{ml}$ and minute 


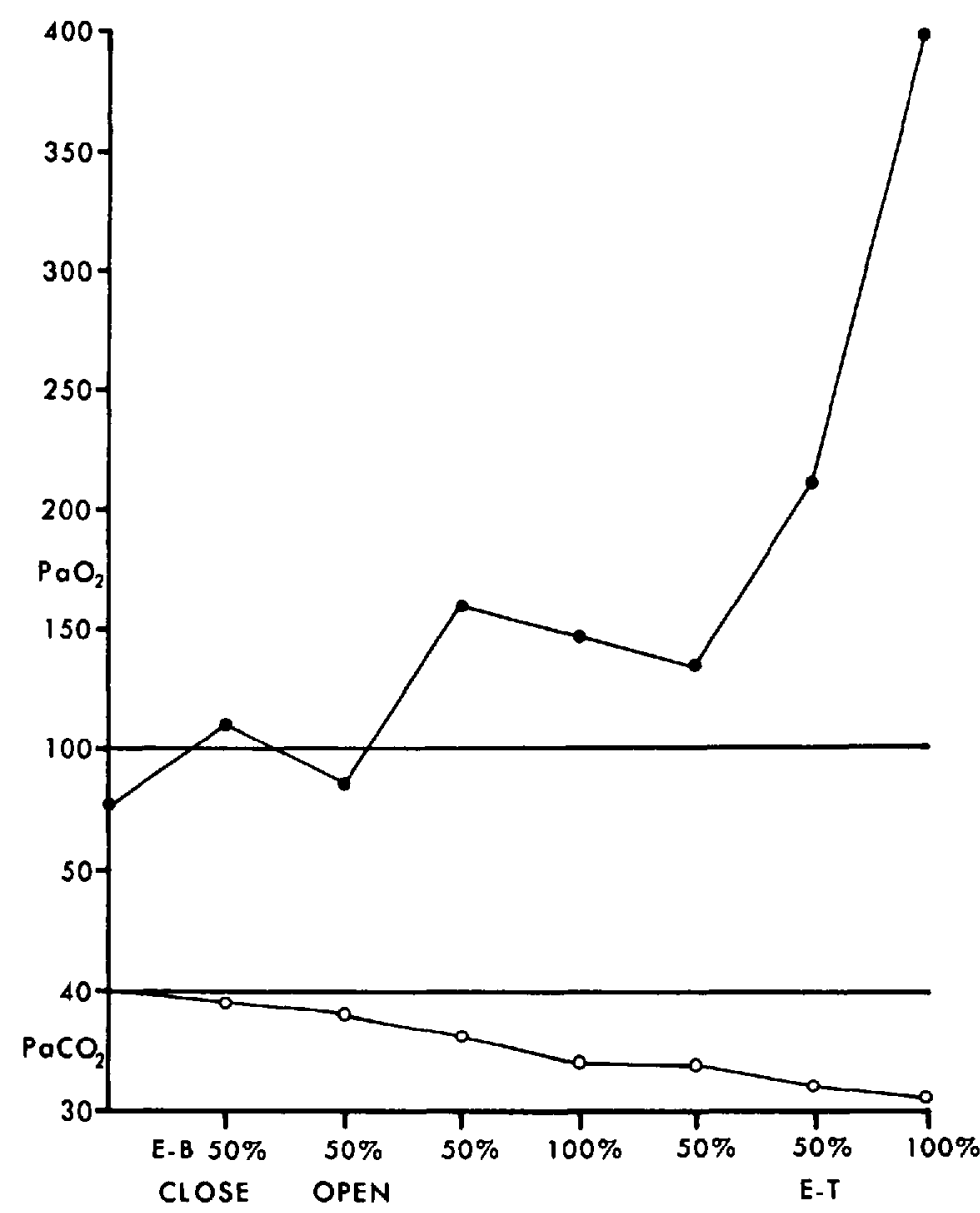

FIGURE 5. Changes in arterial oxygen and carbon dioxide tensions during thoracotomy with varying percentages of oxygen in the inspired mixture. Abbreviations as in Figure 2.

TABLE III

Spontaneous Respiration at 30 Minutes

\begin{tabular}{lccc}
\hline \hline 22 Cases & High & Low & Average \\
\hline $\mathrm{Pa}_{2}(\mathrm{~mm} \mathrm{Hg})$ & 350 & 65 & 151 \\
$\mathrm{PaCO}_{2}(\mathrm{~mm} \mathrm{Hg})$ & 70 & 34 & 51 \\
\hline
\end{tabular}

volume of $8100 \mathrm{ml}$, the arterial carbon dioxide tension was $57 \mathrm{~mm} \mathrm{Hg}$; in case no. 58 , with a tidal volume of $300 \mathrm{ml}$ and a minute volume of $4050 \mathrm{ml}$, the arterial carbon dioxide tension was $57 \mathrm{~mm} \mathrm{Hg}$; in case no. 25, with a tidal volume of 350 $\mathrm{ml}$ and minute volume of $6350 \mathrm{ml}$, the carbon dioxide tension was $41 \mathrm{~mm} \mathrm{Hg}$; and finally, in case no. 49 with tidal volume of $350 \mathrm{ml}$ and minute volume of $4350 \mathrm{ml}$, carbon dioxide tension was $43 \mathrm{~mm} \mathrm{Hg}$. There appeared to be a very marked variation in the breathing pattern in patients with spontaneous respiration. 


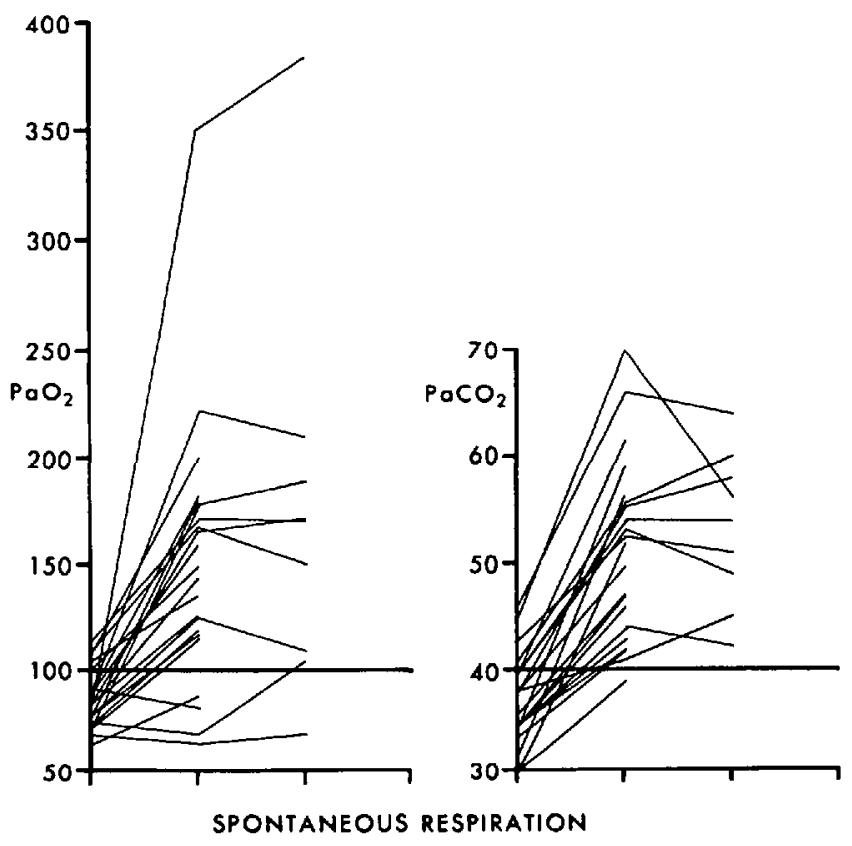

Figure 6. Changes in arterial oxygen and carbon dioxide tension during spontaneous respiration at 30 and 60 minute intervals.
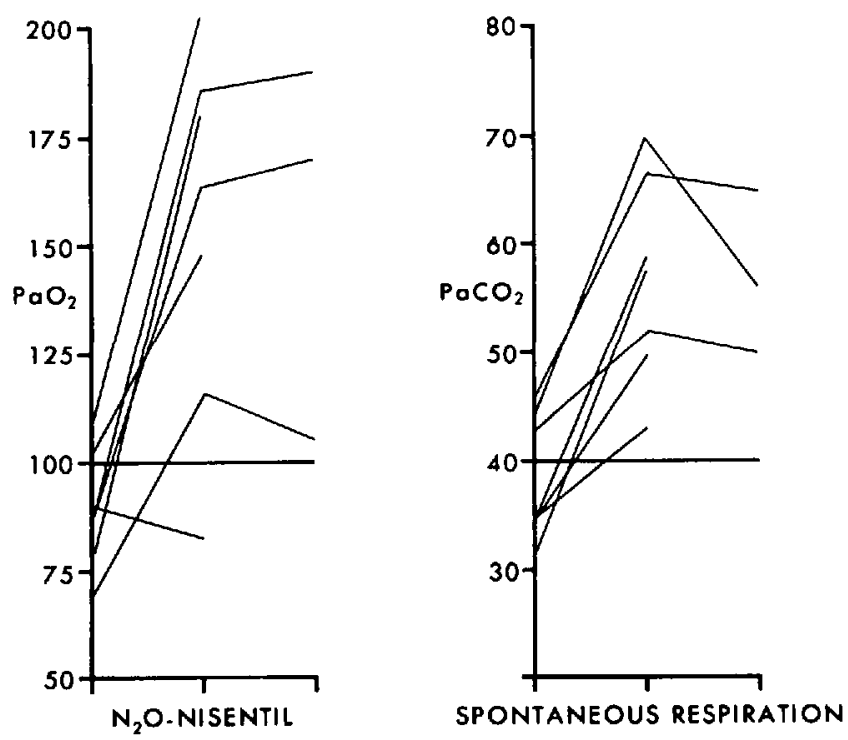

Figure 7. Changes in arterial oxygen and carbon dioxide tensions with spontaneous respiration using a Nisentil-nitrous-oxide technique at 30 and 60 minute intervals. 

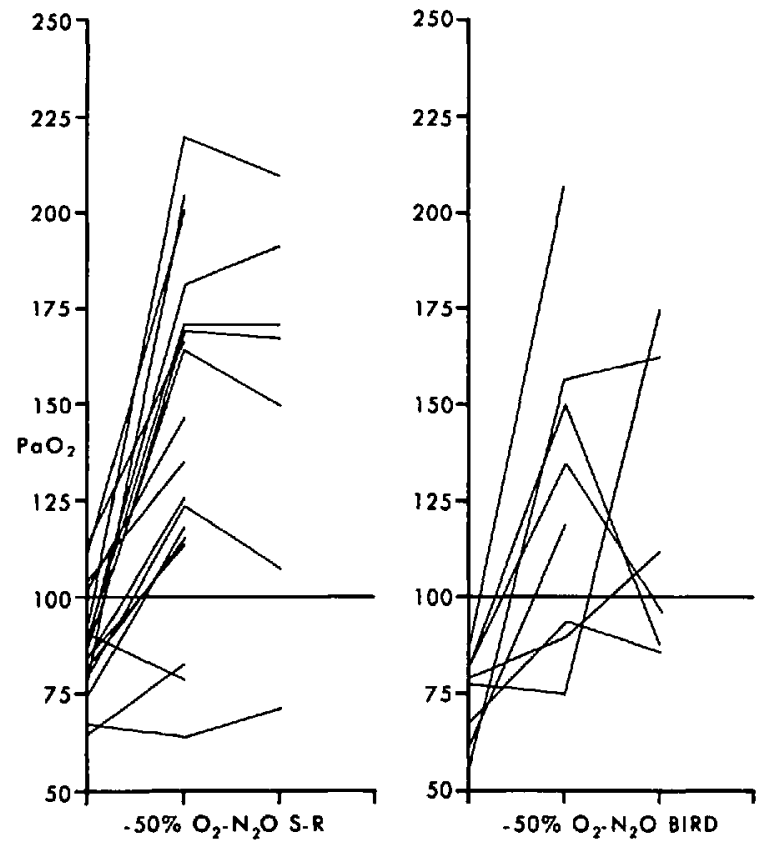

Figure 8. Arterial oxygen tensions with less than 50 per cent inspired oxygen at 30 and 60 minute intervals, (left) during spontaneous respiration and (right) during intermittent positive pressure respiration with the Bird Respirator.

TABLE IV

Spontaneous Respiration vs Bird Respirator

\begin{tabular}{lrccc}
\hline \hline Average $\mathrm{Pa}_{\mathrm{O}_{2}}$ & No. & 30 Minutes & No. & 60 Minutes \\
\hline$<50 \% \mathrm{O}_{2} \mathrm{~S}-\mathrm{R}$ & 18 & $143 \mathrm{~mm} \mathrm{Hg}$ & 7 & $152 \mathrm{~mm} \mathrm{Hg}$ \\
$<50 \% \mathrm{O}_{2}$ Bird & 8 & $128 \mathrm{~mm} \mathrm{Hg}$ & 7 & $111 \mathrm{~mm} \mathrm{Hg}$ \\
\hline
\end{tabular}

TABLE V

BIRD RESPIRATOR < 50\% AND 50\% OXYGEN

\begin{tabular}{lrlcr}
\hline \hline Average $\mathrm{Pa}_{O_{2}}$ & No. & 30 Minutes & No. & 60 Minutes \\
\hline$<50 \% \mathrm{O}_{2}$ & 8 & $128 \mathrm{~mm} \mathrm{Hg}$ & 7 & $113 \mathrm{~mm} \mathrm{Hg}$ \\
$50 \% \mathrm{O}_{2}$ & 13 & $169 \mathrm{~mm} \mathrm{Hg}$ & 8 & $177 \mathrm{~mm} \mathrm{Hg}$ \\
\hline
\end{tabular}

TABLE VI

\begin{tabular}{lcc}
\hline Non-chest cases & Average $\mathrm{Pa}_{2} 30 \mathrm{~min} .(\mathrm{mm} \mathrm{Hg})$ \\
\hline Bird & $<50 \% \mathrm{O}_{2}$ & 128 \\
Bird & $50 \% \mathrm{O}_{2}$ & 169 \\
Bird & $>50 \% \mathrm{O}_{2}$ Cyclo. & 294 \\
S-R & $<50 \% \mathrm{O}_{2}$ & 143 \\
\hline
\end{tabular}



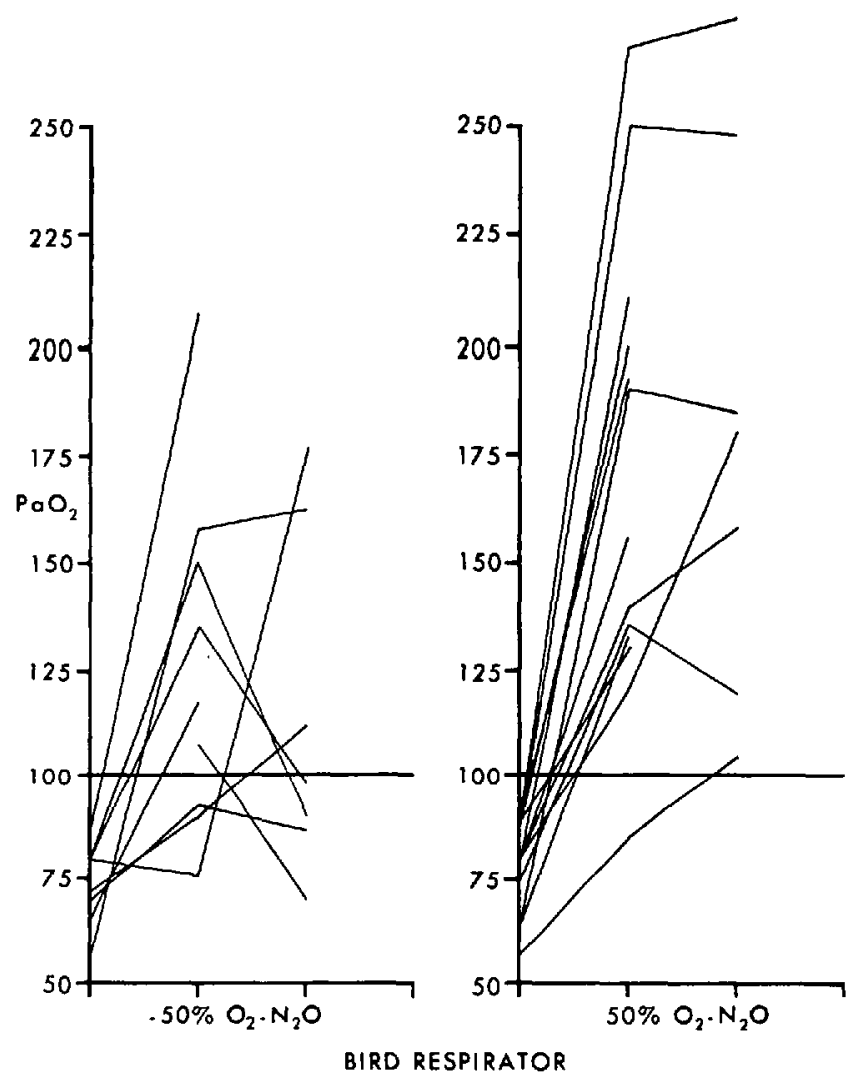

Figure 9. Comparison of arterial oxygen tension with 50 per cent and less than 50 per cent inspired oxygen during intermittent positive pressure respiration with the Bird Respirator at 30 and 60 minute intervals.

\section{Discussion}

Patients arriving in the operating room for anaesthesia show marked variation in the arterial oxygen tension. Age appears to be the only factor consistently affecting the oxygen tension. The arterial oxygen tension tends to decrease as age increases. As seen in Figure 1 the female patients show a greater proportion of higher oxygen tensions. Preoperative arterial oxygen tension should be an integral part of investigation in major or seriously ill patients so that a baseline is available for comparison during and after anaesthesia. A single random oxygen tension reading will be very difficult to interpret. This also applies to the arterial carbon dioxide levels.

\section{Thoracotomy cases}

Thoracotomy cases in which the endobronchial technique is used show very marked disturbances in the blood gases. Once the pleura is opened and the lung 


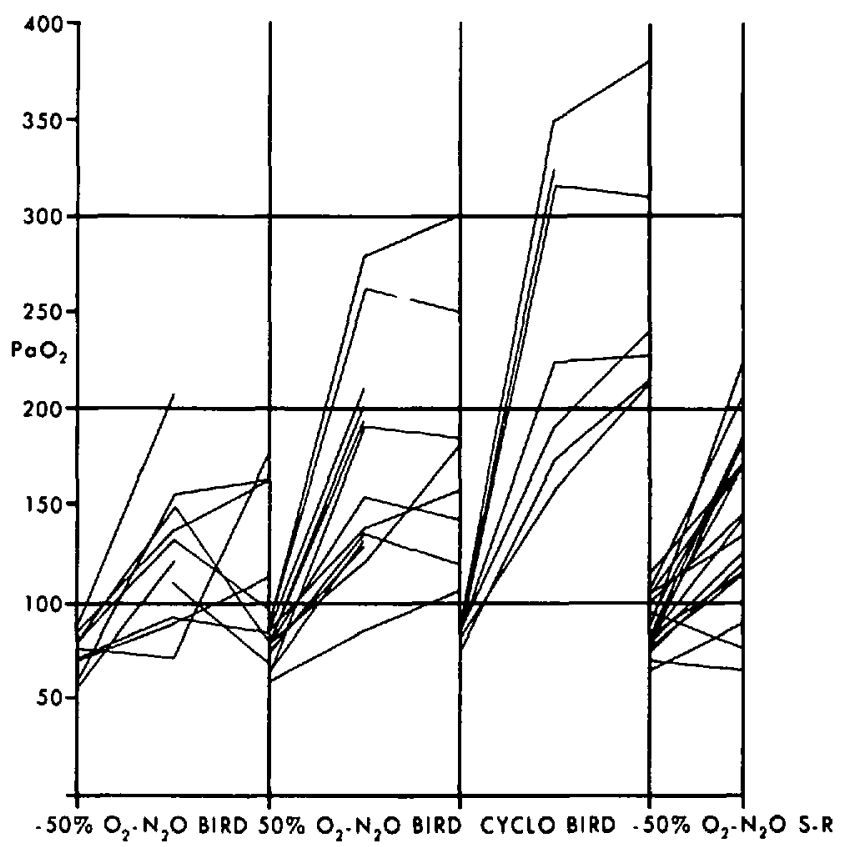

Figure 10. Comparison of arterial oxygen tension using different inspired oxygen concentrations and techniques. BIrD $=$ intermittent positive pressure respiration with the Bird Respirator, cYCLO $=$ cyclopropane, $\mathrm{SR}=$ spontaneous respiration.

is collapsed, there is a significant drop in the arterial oxygen tension compared to the levels prior to the opening of the pleura. The disturbances in arterial oxygen tension have been discussed by various authors. They indicate that there are varying degrees of shunting of blood through the collapsed lung. ${ }^{2-4}$ In some cases, switching to 100 per cent oxygen in the inspired gases may produce no change in the arterial oxygen tensions; or an increase or decrease may result. These effects certainly indicate very marked shunting of blood through the collapsed lung. Once the collapsed lung is inflated the arterial oxygen tension is greatly improved and 100 per cent oxygen provides an arterial oxygen tension in the order of $400 \mathrm{~mm} \mathrm{Hg}$. The arterial carbon dioxide tensions as a rule remain below normal, an indication of adequate carbon dioxide clearance in spite of the shunt mechanism. With the varying degree of shunting of blood through the collapsed lung the use of 100 per cent oxygen in the inspired mixture will not guarantee an arterial tension above $100 \mathrm{~mm} \mathrm{Hg}$. Once the endobronchial anaesthesia is converted to endotracheal anaesthesia, the arterial oxygen tension improves significantly because of the removal of the shunt.

Our results suggest that the endotracheal technique is preferable for thoracotomies even when the lung is partially collapsed. Because of the marked shunting of blood through the collapsed lung, an endobronchial technique may provide low arterial oxygen tensions even though 100 per cent oxygen is used. Generally speaking, the arterial carbon dioxide tension is maintained at a satisfactory level below $40 \mathrm{~mm} \mathrm{Hg}$ with endobronchial anaesthesia. 


\section{Cases with intact thorax}

The group of patients who breathe spontaneously during anaesthesia on the whole have a higher mean arterial oxygen tension as compared with those on intermittent positive pressure respiration. The ventilation is variable during anaesthesia. All patients breathing spontaneously have an increased arterial carbon dioxide tension during anaesthesia. At no time in our study were there clinical signs of hypercarbia even when the arterial carbon dioxide tension reached 70 $\mathrm{mm} \mathrm{Hg}$. Respiratory minute and tidal volume measurements do not indicate the adequacy of carbon dioxide elimination from the patient with spontaneous respiration. Minute volume as high as $8100 \mathrm{ml}$ produced carbon dioxide tensions of $58 \mathrm{~mm} \mathrm{Hg}$, whereas a minute volume of $4050 \mathrm{ml}$ may have a carbon dioxide tension of $57 \mathrm{~mm} \mathrm{Hg}$.

From the foregoing discussion one cannot assume normal arterial carbon dioxide levels by watching the rebreathing bag or measuring the minute and tidal volumes. Is there a level at which arterial carbon dioxide tension shows pathological signs of hypercarbia during general anaesthesia? Certainly in neurosurgical cases any increase in carbon dioxide tension will lead to cerebral vasodilatation and increased intracranial pressure. The increased arterial carbon dioxide tension associated with spontaneous respiration is probably due to depression of the respiratory centre from premedication and anaesthesia. Thus higher arterial carbon dioxide tension is required to stimulate the centre because of the central nervous system depression.

When the arterial oxygen tensions are compared, using intermittent positive pressure respiration, the arterial oxygen tension is a direct function of the inspired oxygen concentration. This is shown in Table VI, where less than 50 per cent oxygen produces a mean oxygen tension of $128 \mathrm{~mm} \mathrm{Hg}, 50$ per cent oxygen produces a mean tension of $169 \mathrm{~mm} \mathrm{Hg}$, and over 50 per cent produces a mean tension of $294 \mathrm{~mm} \mathrm{Hg}$. For practical purposes, oxygen concentrations of 50 per cent or over will maintain an arterial oxygen tension of $100 \mathrm{~mm} \mathrm{Hg}$ or more; with oxygen concentration of less than 50 per cent, a certain number of patients will have arterial oxygen tensions below $100 \mathrm{~mm} \mathrm{Hg}$.

Anaesthetists usually consider the figure of $100 \mathrm{~mm} \mathrm{Hg}$ as physiologically normal for arterial oxygen tension. As shown by the preoperative oxygen tensions, the majority of the tensions for oxygen are below $100 \mathrm{~mm} \mathrm{Hg}$. Because of the nature of the oxygen dissociation curve, the arterial oxygen tension must drop very markedly before there is a significant desaturation of the haemoglobin; for example, an arterial oxygen tension of $60 \mathrm{~mm} \mathrm{Hg}$ will saturate the haemoglobin 91 per cent, a decrease of less than 7 per cent from normal. If we consider the available oxygen, when the cardiac output and haemoglobin concentration remain unchanged a decrease of 7 per cent in available oxygen is rather insignificant. But if the cardiac output and haemoglobin are reduced, then any desaturation of the haemoglobin may be important to the available oxygen. ${ }^{5}$

\section{SUMMARY}

This study shows a very wide range of preoperative arterial oxygen tensions in all age groups so that it is impossible to predict clinically the oxygen status 
without blood gas analysis. Without a preoperative baseline, any random sample will be difficult to interpret.

Thoracotomies are interesting in that there are marked decreases in arterial oxygen tension when the lung is collapsed during endobronchial anaesthesia. Even 100 per cent oxygen in the inspired mixture will not insure an arterial tension of $100 \mathrm{~mm} \mathrm{Hg}$.

Oxygen tension in the patient with an intact thorax is directly related to the oxygen concentration in the inspired gases.

This study indicates that the use of accepted routine anaesthetic techniques and agents in routine surgical cases does not necessarily guarantee that a satisfactory physiological blood gas status will be achieved.

\section{RÉSUMÉ}

Cette étude nous fait découvrir un assez grand écart entre les tensions en oxygène dans le sang artériel avant lopération chez des gens de tout âge de sorte quil est impossible de prédire cliniquement le degré d'oxygénation sans analyse des gaz du sang. Sous un point de comparaison pré-opératoire, il devient difficile d'interpréter un échantillon au hazard.

Les thoracotomies présentent un intérêt particulier, car, au cours de ces opérations, on observe une diminution marquée de la tension en oxygène lorsque, au cours de l'intubation endobronchique, on laisse le poumon s'affaisser. Même en faisant inspirer une atmosphère contenant 100 pour cent d'oxygène, on ne parvient pas à assurer une tension artérielle en oxygène de $100 \mathrm{~mm} \mathrm{Hg}$.

Chez le malade, le thorax fermé, la tension d'oxygène est directement proportionnelle à la concentration en oxygène dans l'air inspiré. Cette étude nous permet de constater que les techniques et les agents anesthésiques de routine acceptés dans les cas de chirurgie ordinaires n'assurent pas nécessairement un équilibre physiologique satisfaisant des gaz du sang du malade.

\section{REFERENCES}

1. Bendixen et al. Hypoxia in Anaesthesia: A Review. Clin. Pharmacol. \& Therap. 6: 510 (1965).

2. Bnown et al. A Study of Oxygenation during Thoracotomy, Canad. Anaesth. Soc. J. 15: 468 (1968).

3. Tarhan et al. Blood Gases and $\mathrm{pH}$ Studies during the Use of the Carlens Catheter. Canad. Anaesth. Soc. J. 15: 458 (1968).

4. BJork et al. Endobronchial Anesthesia. Anesthesiology. 14:60 (1953).

5. Nunv et al. Problem of Oxygenation and Oxygen Transport during Haemorrhage. Anaesthesia. 19: 206 (1964). 